This is an unedited manuscript published in the Journal of Vocational Behavior.

Please note that the published version underwent minor additional editing in style and content.

Complete reference:

Froidevaux, A., Hirschi, A., \& Wang, M. (2016). The role of mattering as an overlooked key challenge in retirement planning and adjustment. Journal of Vocational Behavior, 94, 57-69. doi: 10.1016/j.jvb.2016.02.016.

\title{
The Role of Mattering as an Overlooked Key Challenge in Retirement Planning and Adjustment
}

Ariane Froidevaux ${ }^{a}$

University of Lausanne, Switzerland

Andreas Hirschi ${ }^{b}$

University of Bern, Switzerland

Mo Wang ${ }^{\mathrm{C}}$

University of Florida, United States

${ }^{\text {a }}$ Correspondence concerning this article should be addressed to Ariane Froidevaux, Institute of Psychology, University of Lausanne, Quartier UNIL-Mouline, Bâtiment Géopolis, CH-1015 Lausanne, Switzerland; Tel: +4121 69232 58; e-mail: ariane.froidevaux@unil.ch

${ }^{\mathrm{b}}$ Andreas Hirschi, Institute of Psychology, University of Bern, Fabrikstrasse 8, CH - 3012 Bern, Switzerland. Email: andreas.hirschi@psy.unibe.ch

${ }^{c}$ Mo Wang, Department of Management, University of Florida, PO Box 117165, Gainesville, FL 32611-7165, USA. Email: mo.wang@warrington.ufl.edu

Acknowledgement. We would like to thank Valeria Alterman for proof-reading the final version of this paper.

\begin{abstract}
In an aging society, making a successful transition from work to retirement and achieving good quality of retirement adjustment become major concerns for individuals, organizations, and governments. This paper focuses on the particular role of mattering (i.e., individuals' perceptions that they make a difference in the world) as a critical self-concept dimension that may mediate the impact of social interactions on retirement process at two distinct phases. We conducted two studies using time lagged design (with one-year time interval) among older workers 55 years or older $(N=161$; Study 1$)$ and retirees ( $N=186$; Study 2). Study 1 found that mattering mediated the effects of social support at work on life satisfaction but not retirement planning. Study 2 found that mattering mediated the effects of general social support on positive affect but not life satisfaction. Contrary to our expectation, mattering also did not mediate effects of caregiving activities. Overall, our results suggest that mattering represents a critical mechanism that explains some of the positive associations between social support and retirement adjustment quality.
\end{abstract}




\section{Introduction}

Due to the aging of the Western population, the integration of seniors into society and work has been considered one of the major challenges of the 21st century (Shultz \& Adams, 2007). As numerous workers are now considered older workers (i.e., aged above 40 according to the US Age Discrimination in Employment Act), organizations face the challenge of developing these workers. While career development is often seen as a way of self-realization, relational theory of working (Blustein, 2011) has challenged this idea. This theory places relationships at the core of working life, focusing on how working (e.g., career exploration and career decisionmaking) is shaped by relational experiences, and vice versa. In particular, this theory considers relationships as providers of meaning, mattering, and dignity, which is consistent with Savickas's (2005) proposal that careers are about mattering. As retirement puts into question work-related resources, including relationships at and outside of work, the subjective perception that one makes a difference in the world (i.e., that one matters; Elliott, Kao, \& Grant, 2004) can be threatened. Indeed, more than thirty years ago, Rosenberg and McCullough (1981, p. 179) pointed out that the "problem of retirement is that one no longer matters; others no longer depend upon [retirees]. The reward of retirement [may] be the punishment of not mattering." Therefore, while preparing for and adjusting to the new role as retiree, older workers need to face the question of how to still feel that one is usefulthat one still matters.

Whereas some research has shed light on the positive role of mattering to others as a way of dealing with stressors during the transition to college (Rayle \& Chung, 2007), few authors have linked mattering to retirement issues (e.g., Fazio, 2010; Schlossberg, 1989). Also, to our knowledge, no empirical research has been conducted on the role of mattering regarding the general process of retirement. Nevertheless, it has been suggested that mattering should be a critical variable when considering the self-concept in late adulthood, because of a lack or diminution of role occupancy (e.g., paid work), increasing health problems with age, and the devaluation of older adults in Western societies in general (Fazio, 2007). For instance, a qualitative research on the metaphors of retirement reported that some retirees were in search to find a "sense of being useful members of society" (Sargent, Bataille, Vough, \& Lee, 2011 , p. 320). However, the potentially critical role of mattering at different phases of the retirement process (shortly before and after retirement) remains unexplored.

Our aim in this paper is to contribute to answering Wang, Henkens, and van Solinge's (2011) call for research that would recognize the impact of self-concept in improving predictions of retirement adjustment and planning. While different predictors of retirement adjustment have been identified in the previous literature (e.g., individual and organizational; Wong \& Earl, 2009), this paper focuses on social interactions and resources. We specifically argue that mattering represents a positive self-concept dimension through which received and provided support contribute to increased well-being and better retirement planning in the retirement process. We conducted two studies using time lagged design (with one-year time interval) to collect data from older workers and retirees. Study 1 
explored the relationship between social support at work, mattering, and life satisfaction and retirement planning among older workers. Study 2 extended this investigation to retirees and examined mattering as a mediator that linked effects of general social support and caregiving activities to life satisfaction and positive affect. The contribution of this paper thus lies in applying and empirically testing insights from the mattering literature (e.g., Jung, 2015) and the retirement process literature (e.g., Wang \& Shi, 2014). As such, this paper expands current knowledge on the impact of social interactions on the process of retirement and provides a richer and deeper view on how social interactions (benefitting from and giving to others), may contribute to the retirement process.

\section{Mattering and Social Interactions}

Mattering implies that people are not only connected to others, but that they feel that they are important to others. We herein conceptualize mattering in the broader sense of a person's perceived social contribution, in contrast to interpersonal mattering which refers to mattering to specific individuals (Jung, 2015). Different from self-esteem and mastery, mattering explicitly refers to the self-concept within the relational context (Jung, 2015) and thus represents the interactional aspect of one's self-concept, that is, the part of the self that is developed in interaction with others (Flum, 2015; Schultheiss, 2007). According to Schultheiss (2007), mattering provides a sense of social meaning (i.e., one's meaning to others) and relatedness (i.e., the degree to which one matters in the interpersonal world). To contrast, lacking a subjective feeling of mattering may be associated with feelings of being invisible, peripheral to one's social context, not recognized, and not validated (Flum, 2015; Schultheiss, 2007). Consequently, mattering is hypothesized to contribute to subjective well-being across various life stages (Fazio, 2010; Pearlin \& LeBlanc, 2001). In fact, Marshall (2001) and Fazio (2010) have argued that the perception of mattering to others constitutes an important aspect of the self-concept, which refers to the totality of an individual's feelings and thoughts toward him- or herself as an object of reflection (Owens, Robinson, \& Smith-Lovin, 2010).

In their resource-based dynamic model of retirement adjustment, Wang and colleagues (2011) described social resources as one of the important factors that contribute to subjective well-being at retirement; including retirees' marital status, spouse's working status, marital quality, the social relationships derived from postretirement volunteer work and bridge employment (Wang et al., 2011), and social network and social support (Wang \& Shi, 2014). While social resources were found to represent an important factor related to wellbeing in old age (Dumitrache, Windle, \& Herrera, 2015), few studies have been conducted to examine the impact of social interactions in terms of received and provided support on the general process of retirement (e.g., Chen \& Feeley, 2014). Such sparse research is surprising given the widely recognized positive influence of social support on emotional, social, and physical well-being across the lifespan (Harel, Shechtman, \& Cutrona, 2011) and its identification as a predictor of successful aging (Tovel \& Carmel, 2014). In this paper, we argue that social support at work and social support in general might contribute to a feeling of mattering (e.g., Marshall, 2001; Schultheiss, 2007). First, 
Rohall (2003) suggested that social interactions provide feedback to the individual about his or her contribution to a group. Moreover, believing that others care about us, our goals and futures, was found to increase feelings of mattering (Rosenberg \& McCullough, 1981), while lack of social support may impede the perception that one matters (Rayle \& Chung, 2007).

Second, as social support in the work context provides assistance, advice and potential friendships at work (Humphrey, Nahrgang, \& Morgeson, 2007), we argue that these may in turn increase a feeling of mattering. For instance, receiving fruitful feedback from one's supervisor or coworkers on a specific task may foster these three aspects of mattering. This is also in line with the relational theory of working (Blustein, 2011), according to which mattering represents a way of learning about one's efforts and accomplishments, in this case in the work context. As such, we propose:

Hypothesis 1. Social support at work and social support in general positively predict mattering among older workers and retirees.

\section{Social Support at Work and Mattering in the} Retirement Planning Phase

Retirement planning constitutes the first phase of the retirement process and includes formal (e.g., courses) and informal (e.g., discussions with friends) planning, but also specific financial planning, and retirement goal setting (Wang \& Shultz, 2010). It seems particularly important to investigate the role of social support at work in the retirement planning phase, given that according to work design theory (Humphrey et al., 2007), social support at work represents one of the important social characteristic of work and can be defined as "the degree to which a job provides opportunities for advice and assistance from others" (Morgeson \& Humphrey, 2006, p. 1324), in particular from coworkers and supervisors. Further, older workers seem more likely to put a higher value on relationships at work compared to younger employees (Rohall, 2003), which is in line with socio-emotional selectivity theory (Carstensen, Isaacowitz, \& Charles, 1999).

Research showed that social interactions are important for older workers' retirement planning (Chiesa \& Sarchielli, 2008). In their review, Taylor and Schaffer (2012) reported that social support constitutes a determinant of seeking post-retirement work. Moreover, support from colleagues and friends may increase clarity of retirement goals, which in turn fosters retirement planning (Taylor \& Schaffer, 2012). In particular, social support at work provides opportunities to gain advice and help from others (Humphrey et al., 2007), which may in turn increase motivation for planning and a more future-oriented time perspective (Taylor \& Schaffer, 2012).

As the interactional aspect of the selfconcept, we argue that mattering encourages people to take action, be more confident about action-taking such as concrete retirement planning (e.g., attending courses), and/or initiate changes in one's environment (e.g., decide to work part-time once retired). In particular, we propose that knowing that oneself matters, as a person, may be extended to what one undertakes in terms of activities: Not only oneself, as a person, may matter to others, but also what one will do at retirement. Concretely, planning for retirement may become especially meaningful when individuals know that, in the retirement context, 
they will matter. In contrast, future retirees with low perceptions of mattering may feel that others do not care about what they will do at retirement in terms of activities, thus potentially decreasing motivation for retirement planning. We hence propose:

Hypothesis 2. Mattering mediates the positive effect of social support at work on retirement planning among older workers.

Perceptions of mattering may also increase older workers' life satisfaction. Specifically, we argue that knowing that one is important to specific others such as coworkers and supervisors and to one's community may contribute to a more positive global assessment of one's quality of life. This is also consistent with self determination theory (Ryan \& Deci, 2000), which posits that (work) environments that provide a feeling of relatedness can improve individuals' well-being and social development. Similarly, relational theory of working argues that "optimally, working can provide a sense of mattering that can help to give purpose to one's life" (Blustein, 2011, p. 5). We hence propose:

Hypothesis 3. Mattering mediates the positive effect of social support at work on life satisfaction among older workers.

General Social Support and Mattering in the Retirement Adjustment Phase

According to the temporal process model of retirement, as older workers exit full-time work to become retirees, they enter the retirement adjustment phase (Wang \& Shi, 2014), which refers to how older workers become accustomed to changes during retirement and achieve psychological comfort (van Solinge, 2013). Retirement adjustment quality refers to the outcomes of this process (Wang et al., 2011), such as psychosocial well-being. Few studies have focused on the role of social support and mattering on retirement adjustment. Earlier research has demonstrated that supportive interactions from family and friends were positively associated with life satisfaction among retirees (e.g., Chen \& Feeley, 2014). However, none have tried to examine the mechanisms that explain why social support has such positive outcomes.

Recently, Fazio (2010) has advocated for a growing need to investigate the mechanisms through which social support improve wellbeing, in order to better understand why and when social support is helpful. In this vein, we believe that mattering may represent a critical component to explain how social support may be profitable for retirement adjustment. For example, support from friends may foster mattering, which, in turn, may enhance retirees' perception of their quality of life because of a feeling of continuity in the social sphere (i.e., despite changes in other life spheres). This is in line with the continuity theory of retirement adjustment (Atchley, 1999), according to which supportive social context helps sustain the continuity in selfconcept (i.e., mattering) over the retirement process, which contributes to better retirement adjustment in terms of well-being (Wang et al., 2011). Further, in this paper we focus on the two dimensions that have been proposed to constitute subjective well-being: How people think and feel about their lives (Diener, 1984). Specifically, thinking has been related to cognitive well-being, that is, a cognitive evaluation of one's life in general (e.g., life satisfaction) and specific domains (e.g., job satisfaction); while feeling is in line with affective well-being, that is, the presence of pleasant and unpleasant affects (Luhmann, 
Hofmann, Eid, \& Lucas, 2012). First, perception of mattering may increase life satisfaction. Knowing that one is noticed and that one's needs and successes are cared about may increase one's cognitive evaluation of one's life as satisfactory, because of the cognitive awareness that one's needs for relatedness are met (Ryan \& Deci, 2000). Second, mattering may also increase positive affect, as the subjective perception that one makes a difference in the world (Elliott et al., 2004) may enhance the likelihood of feeling contentment and joy. By contrast, the perception that one is not important for others may lead to negative affect such as sadness. Further, the perception of mattering as a positive self-view may support retirees when they encounter difficulties to adjust to some aspects of their life at retirement, buffering feelings of anxiety, despair, and stress (Thoits, 2011). We hence propose:

Hypothesis 4. Mattering mediates the positive effects of general social support on (a) life satisfaction and (b) positive affect among retirees.

\section{Caregiving Activities and Mattering in the Retirement Adjustment Phase}

Whereas receiving support is an important predictor of well-being, providing caregiving might be critical as well (e.g., van den Bogaard, Henkens, \& Kalmijn, 2014). The common stereotype depicting the elderly as passive recipients of help (Schwarz et al., 2010) may explain why caregiving activities by older adults have generally been overlooked in previous research. In this paper, we focus on caregiving activities defined as "taking care of [grand]children, other family members, aging parents, and loved ones" (Blustein, 2011, p. 8). These activities represent one component of prosocial behavior, along with volunteering, altruism, generativity, and compassion (Midlarsky, Kahana, \& Belser, 2015). Many older adults devote significant time and energy to care for others such as older parents and younger generation dependents, giving them the label of the "sandwich generation" (Shultz \& Wang, 2011). Indeed, a recent study focusing on changes arising in interpersonal relationships after retirement found that once retired, individuals modify the nature of their relationships by providing more instrumental support to family and friends (van den Bogaard et al., 2014).

According to the contributory model of successful aging (Midlarsky et al., 2015), caregiving, along with other prosocial behaviors, represents a central aspect of old age and might be an expression of an intrinsic motivation to help society. Further, previous research reported that people taking care of others were shown to have a higher sense of mattering because they are important to other people and are responsible for their health or well-being (Rohall, 2003). We argue that by providing care to others, retirees can enhance their sense of mattering by feeling that others rely on their support.

Previous research has also investigated the impact of caregiving activities on well-being in retirement, assuming that not only receiving but also providing support may lead to better well-being among the elderly (Kim, Hisata, Kai, \& Lee, 2000). In their recent review, Midlarsky and colleagues (2015) reported that only providing support, but not receiving support, was associated with lower morbidity. Potocnik and Sonnentag (2013) found that volunteering and providing help improved retirees' quality of life for over two years. Schwarz and 
colleagues (2010) reported that providing care represents a source of social approval and social efficacy, as well as autonomy and selfefficacy. More recently, Feeney and Collins (2015) suggested that providing support may foster the experience of positive affect, selfevaluation, and meaning in life, as individuals note that their efforts have been successful and appreciated by others.

We argue that such results shed light on the potential importance of mattering as the explanatory mechanism between caregiving activities and well-being in retirement. Indeed, Piliavin and Siegl (2007) found that mattering mediated the relationship between volunteering and well-being, thus suggesting that volunteering increased psychological wellbeing because individuals felt that they mattered more. As previously argued, mattering may positively impact retirement adjustment as it may represent some continuity into one's self-concept (Atchley, 1999), which may balance discomfort due to other changes experienced in the retirement life. Further, perceptions of mattering may not only increase retirees' overall life satisfaction given the cognitive awareness that their basic need for relatedness is fulfilled (Ryan \& Deci, 2000), but also increase positive affect such as contentment. In contrast, perceptions that one is invisible to others may lead to feeling bad or angry. We hence propose:

Hypothesis 5. Mattering mediates the positive effects of caregiving activities on (a) life satisfaction and (b) positive affect among retirees.

\section{Study 1: Mattering among Older Workers}

Study 1 investigated $\mathrm{H} 1, \mathrm{H} 2$ and $\mathrm{H} 3$ among a sample of older workers in Switzerland. Because the official retirement age in
Switzerland is 64 for women and 65 for men, we decided to investigate older workers with an age of at least 55 years, ensuring that retirement is a relevant and upcoming life transition for the investigated sample.

\section{Method}

Participants. The final longitudinal sample consisted of 161 employees; 93 were women (57.8\%); 37 (23\%) were single, 40 (34.9\%) had a partner without being married, and 84 $(52.2 \%)$ were married. The mean age was 58.55 years $(S D=2.6)$, with an age range between 55 to 64 years old. The average organizational tenure was 18.36 years $(S D=$ 9.41); 99 (61.5\%) worked full time (i.e., minimum of $37 \mathrm{~h}$ a week), 62 (38.5\%) worked part-time. Regarding education, $3(1.9 \%)$ had achieved primary school, 42 (26.1\%) had achieved secondary school (i.e., high school or vocational and education training), 27 (16.8\%) had achieved higher professional education, and $86(53.4 \%)$ had achieved a college or university degree. Regarding income, 34 (21.1\%) earned less than 6,285 USD per month, $70(43.5 \%)$ earned between 6,285 to 12,570 per month, and 49 (30.4\%) earned more than 12,570 USD per month. The average full-time salary in this region of Switzerland was around 6,100 USD per month in 2012 (Office, 2015).

Procedure. We contacted 18 organizations and associations and asked them to send information about the survey and its online link directly to clients or employees aged above 55 years. The final sample consisted of employees or clients from 13 different organizations and associations, including state organizations, HR associations, and providers of retirement planning courses. We were only able to measure participation rate from the 
largest organization in our sample (i.e., a state hospital), which sent the information to 1,341 of their employees, of whom 215 completed the questionnaire. This participation rate of $16 \%$ corresponds to representative estimations of participation rates in Switzerland for individuals aged between 59 and 72 years old for an online questionnaire without participation incentives (Lipps \& Pekari, 2013). In total, 371 older workers answered the questionnaire. At the end of the questionnaire, participants were asked if they agreed to be contacted again one year later: 248 (66.9\%) did agree and 191 (51.5\%) actually completed the second questionnaire. A one-year time gap was chosen because it enabled us to clearly distinguish the predictor and mediator and outcomes over time. In addition, previous research showed that a one-year time gap enabled the control for seasonal effects on well-being (De Lange, Taris, Kompier, Houtman, \& Bongers, 2003) and that the effects of work characteristics (e.g., social support at work) on well-being were quite consistent over a one-year period (Parker, Andrei, \& Li, 2014). Theoretically, according to the conservation of resources theory, (social) resources lead to the accumulation of additional resources over time (Hobfoll, 2002) and we can thus expect that social support leads to a resource gain spiral with increasing levels of mattering over time. However, it might take time for social interactions to be translated into one's self-concept (i.e., sense of mattering) and investigating a time-lag of at least several months thus seems reasonable. Of the 191 respondents, 161 (84.3\%) reported that they were still working and 33 (17.3\%) indicated that they had retired within the last 12 months (i.e., receiving their retirement pension). For the final sample, we kept only the 161 older workers who answered at both waves and had not retired at wave 2 . Social support at work was measured at T1, mattering, life satisfaction, and retirement planning at T2. We conducted one-way ANOVAs to examine potential differences in individual control variables and predictors at $\mathrm{T} 1$ between those who completed the second wave and those who did not. We found a significant effect of chronological age at $\mathrm{T} 1$ on participation in the study at T2 $(p<.01)$, with participants of both waves being significantly younger than those who dropped out.

Measures. Table 1 shows Cronbach's alpha estimates, means, standard deviations, and bivariate correlations of the applied measures. Unless otherwise stated, measures were independently translated from their original English version into French, by two native French-speaking psychologists familiar with the constructs. A final version was conceived by resolving any discrepancies between the two translations and deciding on a final version that best reflected the original meaning of the items.

Social support at work. We used Morgeson and Humphrey's (2006) six-item subscale of social support at work from the Work Design Questionnaire (WDQ), with a five-point Likert response format ranging from 1 (strongly disagree) to 5 (strongly agree). A sample item is: "People I work with take a personal interest in me." Support for the reliability, validity, and factor structure of the scale has been established in different studies (Stegmann et al., 2010), for example by showing positive relations to post-retirement work with the same employer (Wöhrmann, Deller, \& Wang, 2013). 
Mattering. Mattering was assessed by the five-item General Mattering Scale (GMS) developed by Rosenberg and McCullough (1981) and finalized by Marcus (1991), with a four-point Likert response format ranging from 1 (few) to 4 (very strongly). It aims to measure individuals' perception that they matter not to specific individuals but in the more general form as the perception of making a difference in the world (Rayle, 2005). A sample item is: "How important do you feel you are to other people?"

Table 1

Summary of Bivariate Correlations, Means, Standard Deviations, and Cronbach's Alphas among the Assessed Constructs in Study 1

\begin{tabular}{lllllll}
\hline Measure & 1 & 2 & 3 & 4 & $M$ & $S D$ \\
\hline 1. Social support at work (T1) & $(.81)$ & & & & 24.84 & 3.94 \\
2. Mattering (T2) & $.35^{\star *}$ & $(.85)$ & & & 14.08 & 2.95 \\
3. Life satisfaction (T2) & $.20^{\star}$ & $.28^{\star *}$ & $(.90)$ & & 27.68 & 5.42 \\
4. Retirement planning (T2) & .06 & .09 & .12 & $(.79)$ & 15.46 & 4.62
\end{tabular}

Note. Older workers, $N=161$; entries in parentheses in diagonal are Cronbach's alpha coefficients.

${ }^{*} p<.05 ;{ }^{* *} p<.01$

This scale has been widely used in studies investigating general mattering with different populations (e.g., adolescents, urban communities, army officers), demonstrating positive relationships with overall wellness, social interactions, and negative relationships with depression (e.g., Rayle, 2005; Rohall, 2003; Taylor \& Turner, 2001).

Life satisfaction. We applied the Satisfaction with Life Scale (SWLS) developed by Diener, Emmons, Larsen and Griffin (1985) assessing the overall perception of one's satisfaction with life according to one's own criteria, in its French version (Blais, Vallerand, Pelletier, \& Brière, 1989). It is a five-item scale with a seven-point Likert response format ranging from 1 (strongly disagree) to 7 (strongly agree). A sample item is: "In most ways my life is close to my ideal." A recent research synthesis of the validity of SWLS has reported good internal reliability for the French version of the scale ( $\alpha=.80$ to .84 ) across samples of students and older adults (Shankland \& Martin-Krumm, 2012).

Retirement planning. We used Lim's (2003) seven-item retirement planning questionnaire, with a four-point Likert response format ranging from 1 (never) to 4 (often). Respondents were asked about the frequency at which they engaged in various planning activities such as "attending a pre-retirement program", "read about retirement", or "discuss retirement with others."

Control variables. We measured at $\mathrm{T} 1 \mathrm{a}$ range of control variables for which previous research showed significant relationships with retirement-related outcomes: sociodemographical (i.e., gender, chronological age, nationality, education, income, marital status, spouse working status), individual (i.e., subjective age, subjective life expectancy, physical and chronic health problems), retirement-related (i.e., intended retirement age, voluntariness of retirement), and work context (i.e., job tenure, psychological job 
demands, and task significance) variables. However, none of these variables correlated significantly with the predictor and outcome variables in our model. Hypotheses testing with or without these control variables yielded the same results. In order to maximize power and provide more interpretable results we thus report the results without controls.

\section{Results}

Empirical distinctness of the assessed variables. Prior to testing the mediation models, we wanted to establish the empirical distinctness of the measured constructs with confirmatory factor analysis (CFA) using Mplus 7 (Muthén \& Muthén, 1998-2012) and the maximum likelihood estimator. Our proposed model that specified social support at work, mattering, life satisfaction, and retirement planning, as distinct but correlated factors, indicated by their respective items, showed significantly better fit $\left(X^{2}=412.13\right.$; RMSEA $=$ .07 ; $\mathrm{SRMR}=.08 ; \mathrm{CFI}=.87$ ) than (1) a onefactor model $\left(X^{2}=1113.3\right.$; RMSEA $=.16$; SRMR $=.17 ; \quad \mathrm{CFI}=.37 ; p<.001)$ that combined the four variables into one factor; (2) a two-factor model in which social support at work and mattering were treated as one factor and life satisfaction and retirement planning as a second factor $\left(X^{2}=801.08\right.$; RMSEA $=.13$; SRMR = .13; CFI = .60; $p<.001)$; and (3) a three-factor model in which social support at work was conceived as one factor, mattering as another factor, and life satisfaction and retirement planning as a third factor $\left(X^{2}=\right.$ 653.58; RMSEA = .11; SRMR = .12; CFI = .70; $p<.001)$. Thus results support the empirical distinctness of the assessed constructs.

Latent mediation model. To test $\mathrm{H} 1$ positing a direct effect of social support at work on mattering, and $\mathrm{H} 2$ and $\mathrm{H} 3$, positing an indirect effect of received social support on retirement planning and life satisfaction through mattering, we calculated a mediation model with the bootstrapping approach and 5,000 bootstrapping samples in Mplus, as described by Preacher and Hayes (2008). The bootstrapping procedure does not require multivariate normality in the data or normal distributions of the total and specific indirect effects. This method provides bias-corrected confidence intervals that can be used to estimate true population effects (Preacher \& Hayes, 2008).

Results of the mediation analysis (see Figure 1) showed that social support at work exhibited a significant positive direct effect on mattering ( $\beta=.40, p<.01$ ), which confirmed $\mathrm{H} 1$. In addition, general mattering was significantly positively related to life satisfaction $(\beta=.24, p<.01)$, but not to retirement planning ( $\beta=.04, p>.05)$. The specific indirect effect from social support trough mattering on life satisfaction was significant (bootstrap estimate $=.10, S E=.04, \mathrm{Cl}=.02, .18)$, supporting H3. However, we found no significant indirect effect through mattering on retirement planning (bootstrap estimate $=.01$, $S E=.04, \mathrm{Cl}=-.06, .09$ ), failing to support $\mathrm{H} 2$. The model explained $15.8 \%$ variance in mattering; $11 \%$ in life satisfaction; and $1 \%$ in retirement planning.

\section{Study 2: Mattering among Retirees}

Study 2 investigated $\mathrm{H} 1, \mathrm{H} 4$, and $\mathrm{H} 5$ among a sample of retirees. We put no age limit, in order to have a more representative sample of various durations spent in retirement. Such a diverse sample in terms of age and retirement duration is especially interesting to consider when investigating retirement adjustment quality in relation to 
mattering. In this paper, we defined retirees as people who were receiving a retirement pension (Ekerdt, 2010).

\section{Method}

Participants. The final longitudinal sample consisted of 178 retirees; 96 women (53.9\%); 58 (32.6\%) single, $19(10.7 \%)$ had a partner without being married, and 101
$(56.7 \%)$ were married. The mean age was 68.4 years $(S D=5.26$, age range: 58-83). The average work experience prior to retirement was 23.17 years $(S D=8.23)$; $53(29.8 \%)$ were working besides receiving retirement pensions (i.e., bridge employment); 1 (0.6\%) had achieved primary school, 55 (30.9\%)

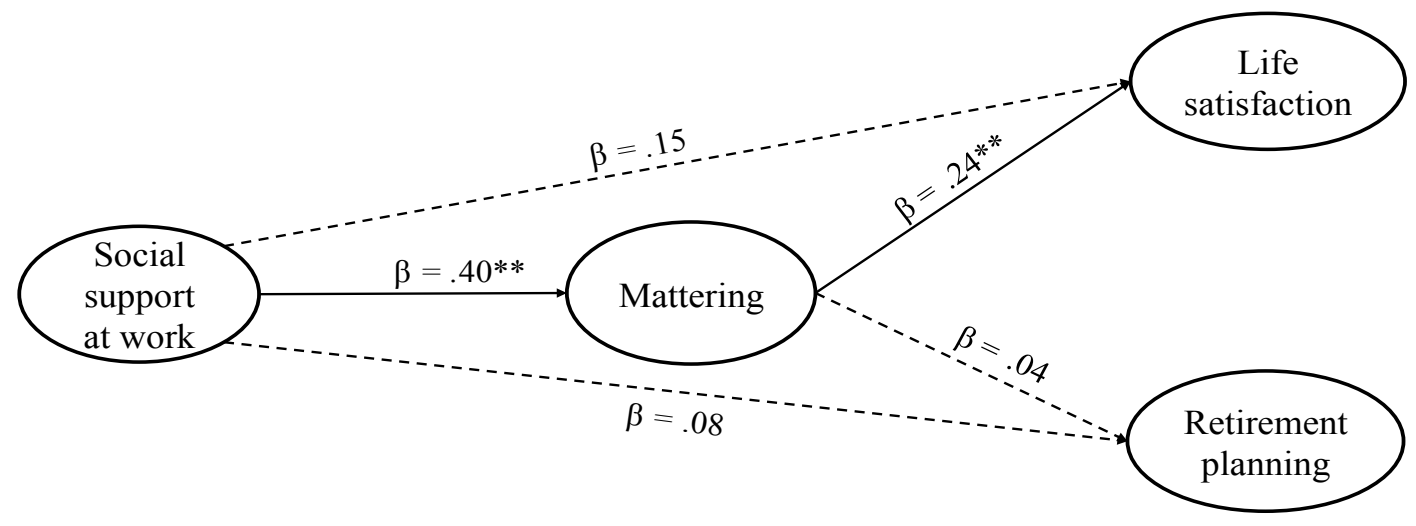

Figure 1. Standardized path coefficients and correlations for the tested mediation models in Study 1 (older workers sample; $N=161$ ). Dashed lines represent nonsignificant direct effects. Social support at work has been measured at T1, mattering, life satisfaction and retirement planning at T2.

${ }^{*} p<.05 ;{ }^{* *} p<.01$

had achieved secondary school (i.e., high school or vocational and education training), $528(15.7 \%)$ had achieved higher professional education, and 94 (52.8\%) had achieved a college or university degree. Regarding income, 67 (37.6\%) earned less then 6,285 USD per month, 93 (52.3\%) earned between 6,285 to 12,570 per month, and $18(10.1 \%)$ earned more than 12,570 USD per month. This income may stem from different sources. First, state-funded pensions that are received at the official retirement age; second, employer funded pensions; third, personal retirement savings, and fourth, bridge employment. Only $11(6.2 \%)$ were solely receiving their employerfunded pension (indicating an early retirement), while the other 167 (93.8\%) also received the state-funded pension (i.e., had reached the official retirement age).

Procedure. We sent information regarding the study to 12 associations for retirees and asked them to send information about the survey and its online link directly to their members. As in Study 1, we were only able to measure participation rate from the largest association in our sample (i.e., 
university for seniors), which sent the information to 962 of their members, 200 of whom completed the questionnaire. Such participation rate of $20 \%$ is a bit higher than representative estimations of participation rates in Switzerland for such age group and procedure (Lipps \& Pekari, 2013). In total, 335 retirees completed the questionnaire. Similarly to Study 1, participants were asked if they agreed to be contacted one year later for the second wave of the study. While 279 (83.28\%) accepted, $178(53.13 \%)$ actually completed the second questionnaire, constituting the final sample used in this study. Caregiving activities and social support were assessed at T1, mattering, life satisfaction, and positive affect at T2. We chose the one-year time lag based on the empirical and theoretical arguments presented in Study 1, assuming that positive social interactions in terms of caregiving and support lead to resource-gain spirals that increase mattering, life satisfaction, and positive affect over time. We conducted a oneway ANOVA to control for differences in the variables assessed at $\mathrm{T} 1$ between those who completed the second wave and those who did not and found a significant effect of chronological age at T1 on participation in the study at T2 $(p<.01)$, with participants at both waves being significantly younger than those who dropped out.

Measures. Table 2 shows Cronbach's alpha estimates, means, standard deviations, and bivariate correlations of the applied measurement scales. The same scales for mattering and life satisfaction were used as described in Study 1.

Social support. We used Schultz and Schwarzer's (2003) perceived social support scale from the Berlin Social Support Scales (BSSS) in its French version (Schwarzer, Schulz, \& Katsap, 2000). Four items assess emotional support (e.g., "Whenever I am not feeling well, other people show me that they are fond of me") and four items measure informational support (e.g., "There are people who offer me help when I need it"), all with a four-point Likert response format ranging from 1 (strongly disagree) to 4 (strongly agree). Whereas the scale was originally developed to measure coping with illness, it has also been used for research on subjective well-being (Scholz, Kliegel, Luszczynska, \& Knoll, 2012) and career patterns (Reitzle, Korner, \& Vondracek, 2009).

Table 2

Summary of Bivariate Correlations, Means, Standard Deviations, and Cronbach's Alphas among the Assessed Constructs in Study 2

\begin{tabular}{lllllllll}
\hline Measure & 1 & 2 & 3 & 4 & 5 & 6 & $M$ & $S D$ \\
\hline 1. Income (T1) & - & & & & & & - & - \\
2. Social support (T1) & $.19^{*}$ & $(.93)$ & & & & & 26.82 & 5.34 \\
3. Caregiving activities (T1) & .11 & $.16^{*}$ & $(.64)$ & & & & 16.37 & 6.99 \\
4. Mattering (T2) & .12 & $.47^{* *}$ & .12 & $(.86)$ & & & 13.02 & 3.02 \\
5. Life satisfaction (T2) & $.24^{\star *}$ & $.43^{\star *}$ & -.01 & $.33^{* *}$ & $(.84)$ & & 28.18 & 4.71 \\
6. Positive feelings (T2) & .14 & $.23^{* *}$ & -.05 & $.29^{* *}$ & $.51^{* *}$ & $(.81)$ & 24.77 & 2.63 \\
\hline
\end{tabular}

Note. Retirees, $N=178$; entries in parentheses in diagonal are Cronbach's alpha coefficients. $p<.05 ;{ }^{* *} p<.01$ 
Caregiving activities. Our 6-item measure of caregiving activities was adapted from two scales (Grundy \& Henretta, 2006; Silverstein, Conroy, \& Gans, 2012) in order to encompass the most important variety of provided informal care, which measured provision of help (9 items) and filial norm of responsibility (6 items). In our study, respondents were asked whether they had been doing one of six tasks for a relative who needed their help during the last year: (1) household chores, which were composed of Grundy and Henretta's (2006) 4 items (meals; cleaning ironing; paperwork; gardening and house repairs) and 2 items from Silverstein and colleagues' (2012) (household chores and repair, financial affairs); transportation/shopping, composed of Grundy and Henretta's (2006) 2 items (shopping, giving lifts in your car) and from Silverstein and colleagues' (2012) 1 item (transportation); (3) help when s/he was sick, composed of Silverstein and colleagues' (2012) 1 item (medication); (4) assistance with personal care, composed of Silverstein and colleagues' (2012) 1 item (personal and health-care needs); (5) financial help, composed of Grundy and Henretta's (2006) 1 item (helping with money) and from Silverstein and colleagues' (2012) 1 item (financial support); and (6) helping looking after grandchildren, composed of Grundy and Henretta's (2006) 1 item (looking after children). An eight-point Likert response format ranging from 1 (never) to 8 (everyday) and general introduction question from provision of help scale (Grundy \& Henretta, 2006) were used.

Positive affect. We used the Positive Feelings subscale from the Scale of Positive and Negative Experience (SPANE) (Diener et al., 2010), which was designed to measure subjective feelings of well-being and ill-being as a state. This six-item subscale asks respondents about the frequency they experience positive emotional states such as "contented", "pleasant", or "joyful", with a fivepoint Likert response format ranging from 1 (hardly ever) to 5 (almost every time). Support for the reliability, validity, and latent factor structure of the scale has been recently confirmed among English-speaking university students (Howell \& Buro, 2015), Japanese college students (Sumi, 2014), Turkish high school students (Telef, 2013), Portuguese fulltime employees adults and university students (Silva \& Caetano, 2013), and Serbian adolescents and young adults (Jovanovic, 2015).

Control variables. We used the same procedure described in Study 1 and assessed the same range of potential control variables at T1. However, only income correlated significantly with the predictor and outcome variables in the model (see Table 2). We hence included this variable as control in the subsequent analysis also because previous research demonstrated that household income (i.e., financial status) positively impacts retirement adjustment quality (Pinquart \& Schindler, 2007; Wang et al., 2011). Indeed, financial resources represent one of the important factors that contribute to subjective well-being at retirement according to the resource-based dynamic model of retirement adjustment (Wang et al., 2011).

\section{Results}

Empirical distinctness of the assessed variables. With the same procedure outlined in Study 1, we evaluated the empirical distinctness of the measured constructs. A five- 
factorial model that specified social support, care, mattering, life satisfaction, and positive affect by their respective items proved to be a significantly better fit ( $X^{2}=628.13$; RMSEA = .06 ; $\mathrm{SRMR}=.06 ; \mathrm{CFI}=.90)$ than $(1)$ a onefactor model $\left(X^{2}=1522.93\right.$; RMSEA $=.13$; SRMR $=.13 ; \mathrm{CFI}=.51 ; p<.001) ;(2)$ a twofactor model which combined social support, care, and mattering in one and life satisfaction and positive affect in another factor $\left(X^{2}=\right.$ 1134.1; RMSEA = .10; SRMR = .10; CFI = .68; $p<.001$ ); (3) a three-factor model in which social support and care were conceived as one factor, mattering as another factor, and life satisfaction and positive affect as a third factor $\left(X^{2}=893.73 ; \mathrm{RMSEA}=.08 ; \mathrm{SRMR}=.08 ; \mathrm{CFI}\right.$ $=.78 ; p<.001)$; and (4) a four-factor model treating social support as a first factor, care as a second, mattering as a third, and life satisfaction and positive affect as a fourth factor $\left(X^{2}=752.13\right.$; RMSEA $=.07$; SRMR $=$ $.07 ; \mathrm{CFI}=.84 ; p<.001)$. Thus results support the empirical distinctness of the assessed constructs.

Mediation model. We conducted the same analyses as described in Study 1 to test $\mathrm{H} 4$, positing significant indirect effect of received social support on subjective wellbeing (i.e., life satisfaction and positive affect) through mattering. Study 2 also enabled to test $H 5$, which proposed significant indirect effect of caregiving activities on subjective well-being (i.e., life satisfaction, positive affect) through mattering. The results of the mediation analyses (see Figure 2) showed that social support exhibited a significant positive direct effect on mattering $(\beta=.53, p<.01)$, confirming $\mathrm{H} 1$ also for retirees. Further, social support exhibited a significant positive direct effect on life satisfaction $(\beta=.34, p<.01)$, but not on positive affect $(\beta=.14, p>.05)$; whereas caregiving activities showed no significant direct effects on either life satisfaction ( $\beta=-.03, p>.05$ ) or positive affect $(\beta=-.05, p>.05)$. In addition, mattering had a specific direct effect on positive affect $(\beta=.29$, $p<.01)$, but not on life satisfaction $(\beta=.16, p$ $>.05)$.

Moreover, the specific indirect effect through mattering was significant for social support on positive affect (bootstrap estimate $=$ $.15, S E=.06, \mathrm{Cl}=.04, .27)$, confirming $\mathrm{H} 4 \mathrm{~b}$. However, we did not find an indirect effect of mattering for the relationship between social support and life satisfaction (bootstrap estimate $=.08, S E=.05, \mathrm{Cl}=-.02, .19)$, not supporting H4a. Further, caregiving activities demonstrated no significant specific indirect effect through mattering on either life satisfaction (bootstrap estimate $=.01, S E=$ $.01, \mathrm{Cl}=-.02, .03)$; or positive feelings (bootstrap estimate $=.01, S E=.03, \mathrm{Cl}=-.06$, .07 ), not supporting $\mathrm{H} 5 \mathrm{a}$ and $\mathrm{H} 5 \mathrm{~b}$. The model explained $28.8 \%$ of variance in mattering; $24.9 \%$ in life satisfaction; and $16.5 \%$ in positive affect.

\section{General Discussion}

The purpose of this paper was to provide a richer and deeper view on how social interactions (benefitting from and giving to others) may contribute to the retirement process. We explored the particular role of mattering as a critical self-concept dimension, through which received and provided support contribute to increased well-being and better retirement planning in the retirement process. As stated by the recent relational theory of working (Blustein, 2011), placing relationships at the core of working life enables to focus on 
the relational outcomes of working such as mattering. With the diminution of the worker role associated with the retirement process, working's impact on the perception of mattering (Blustein, 2011) may decrease. Therefore, our studies were guided by the main research question of how older workers and retirees can still feel useful and important when exiting the work role and entering the retirement process. More specifically, we explored the role of mattering as a critical selfconcept dimension in the retirement process regarding its impact on retirement planning and adjustment.

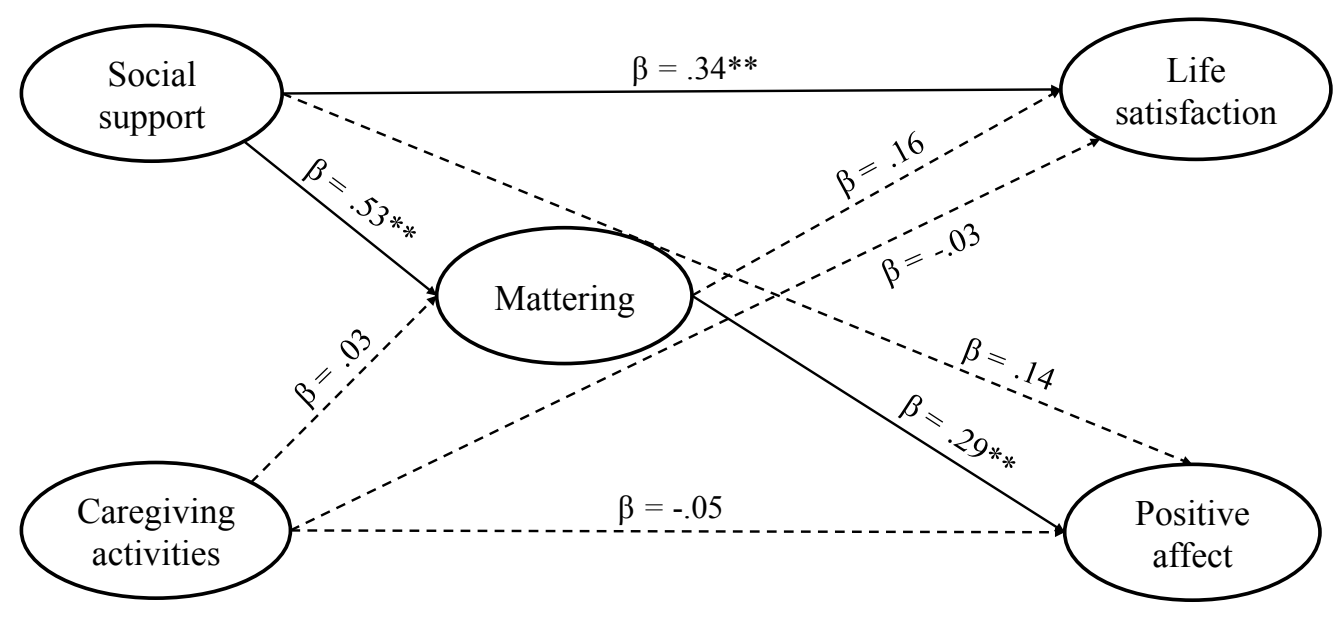

Figure 2. Standardized path coefficients and correlations for the tested mediation models in Study 2 (retirees sample; $N=178$ ). Dashed lines represent nonsignificant direct effects. Social support and caregiving activities have been measured at T1, mattering, life satisfaction and retirement planning at T2. The results are controlled for income (not shown).

${ }^{*} p<.05 ;{ }^{* *} p<.01$

\section{Principal Findings and Directions for Future} Research

We addressed these research questions by conducting two studies using a time lagged design among older workers and retirees. Study 1 explored the relationship between social

support at work, mattering, and life satisfaction and retirement planning among older workers.

The results confirmed that social support at work positively predicts older workers' perception of mattering; and that mattering positively predicts their perceived life satisfaction. However, we observed no direct effect on retirement planning. Further, mattering was found to mediate the relationship of social support at work with life satisfaction, but not with retirement planning. Study 2 extended this investigation to retirees and examined mattering as a mediator that linked effects of general social support and caregiving activities to life satisfaction and positive affect. The results confirmed that general social support, but not caregiving activities, predicts mattering; and that 
mattering positively predicts positive affect.

The results also revealed that mattering mediates the effect of general social support on positive affect, but not on life satisfaction. However, we could not find any mediation effect of mattering on the relationship between caregiving activities and either positive affect or life satisfaction.

First, this paper contributes to literature on mattering in the work context (Jung, 2015). We investigated mattering with two specific groups (i.e., older workers and retirees), which allowed for a richer exploration of the functioning of mattering during the retirement process. Our paper provides more information about the interpersonal factors that may affect perceptions of mattering, as well as their consequences on retirement planning and well-being. Notably, this paper represents the first attempt to our knowledge to explore the relationship between mattering and life satisfaction. Moreover, we contribute to answer Jung's (2015) call for more research on mattering understood as how people view their contribution to society (i.e., rather than interpersonal mattering to specific others). Second, this paper enables to deepen our understanding of how social resources may impact retirement adjustment, thus contributing to enrich current knowledge regarding the resource-based dynamic model of retirement adjustment (Wang et al., 2011). Focusing in particular on social interactions, we investigated how they influenced perception of mattering, and how, in turn, such perception contribute to retirement planning and adjustment quality. Future research may investigate the role of mattering as mediating the relationship between other resources (e.g., motivational, emotional) and retirement outcomes.

In particular, this paper provides three general insights for studying mattering in the retirement process. A first main finding of this paper is that we reported differences depending on group (older workers vs. retirees) and type of well-being (i.e., cognitive vs. affective; Diener, 1984) regarding the role played by mattering. Specifically, we found that mattering mediates the relationship between social support at work and life satisfaction for older workers; and between general social support and positive affect, but not life satisfaction, for retirees. Contrary to Fazio's (2010) general assumption that mattering would represent a mechanism through which social support improves well-being, our studies imply that this applies to specific cases only. While having a positive self-view as mattering may explain why social interactions lead to higher life satisfaction before entering retirement; once entering retirement life, such positive self-view becomes important to explain why social interactions lead to higher positive affect. Such a distinction can be related to socio-emotional selectivity theory (Carstensen et al., 1999) according to which, as people age, a growing importance will be attributed to social interactions as fulfilling older adults' emotional needs and goals. We believe that our findings contribute to specify the kind of interpersonal contacts involved in such mechanisms for elderly people, clarifying that social interactions positively impact positive affect at retirement because they enhance one's perception of mattering. Indeed, we did not find a specific direct effect from social support on positive affects, which supports the assumption that social 
interactions in themselves are not sufficient to contribute to more positive affect at retirement. In addition, the importance of emotional resources has been highlighted by the resource-based dynamic model of retirement adjustment (Wang et al., 2011). In this vein, future research focusing on the relationship between retirees' social and emotional resources (Wang et al., 2011) may be particularly helpful. Notably, the effect of emotional stability, as a personality trait, on perceptions of mattering might be explored.

A second main contribution of this paper to previous literature is the fact that mattering did not explain the relationships between social support at work and retirement planning for older workers. In addition, neither social support at work nor mattering seemed to impact retirement planning, which is in contradiction with previous research reporting an impact of social support at work on retirement planning (Taylor \& Schaffer, 2012; Wöhrmann et al., 2013). Indeed, mattering does not seem to foster motivation to take action through elaborating concrete retirement plans. An alternative explanation might be that mattering may not only provide motivation to take action, but also a general sense of confidence into life and one's future, so that whatever one may undertake at retirement, one will remain important for others and make a difference in the world around him or her. Mattering as part of one's self-concept may transcend the different social contexts in which one may be involved in retirement. In that case, retirement planning would become unnecessary, because individuals would not worry about their usefulness at retirement and, in turn, feel no need to plan in which contexts they might be useful in their future retirement.
This is in line with Schlossberg's (2009) notion of easy gliders, used to describe how some older adults may envision retirement as taking each day as it comes, within an unstructured time. Thus, it is possible that motivation to take action and general sense of confidence resulting from mattering may play the role of a push factor and a pull factor, respectively, regarding retirement planning, thus inhibiting each other. This may explain the neutral relationship observed between mattering and retirement planning. Clearly, future research is needed regarding the relationship between mattering and retirement planning. For instance, it may investigate if other aspects of the self-concept, such as mastery or selfesteem, may be related to retirement planning.

A third main finding of this paper is that caregiving activities were not related to either mattering or retirement adjustment quality one year later (i.e., life satisfaction and positive affect), either directly or indirectly. This result is in contradiction with previous research that reported a positive impact of caregiving activities on mattering (Rohall, 2003) and on retirement adjustment quality (Midlarsky et al., 2015; Potocnik \& Sonnentag, 2013). In addition, while Piliavin and Siegl (2007) reported that mattering mediated the relationship between volunteering and wellbeing, suggesting that volunteering enables people to feel that they fulfill an important role for society, we did not find a similar indirect effect through mattering regarding caregiving activities. This suggests that caregiving activities may not represent a way of contributing to society that is subjectively as important as work prior to retirement. An alternative hypothesis might be that social contribution through volunteering activities 
might be more recognized by society than caregiving. In fact, volunteering often takes place within a specific structure such as an association, with specific aims and goals. By contrast, caregiving activities are more informal by definition, as taking care of family members and loved ones (Blustein, 2011) may be recognized by a more restricted social network, thus leading to lower perception of mattering as a social contribution. More research is thus needed to determine the distinctive-or similar-role of formal (e.g., volunteering) versus informal (e.g., care) provided social support on subjective wellbeing at retirement, and its indirect effect through mattering. Such research would further enable to specify the characteristics and differences between these two different types of prosocial behaviors (Midlarsky et al., 2015). Further, the absence of impact of caregiving activities on mattering and retirement adjustment quality may be also due to mutual inhibition of push and pull factors. On the one hand, caregiving activities may lead to greater mattering as it seems to emerge from one's efforts in social interactions (Blustein, 2011), which in turn may increase retirement adjustment quality because of greater continuity of one's self-concept (Atchley, 1999). On the other hand, caregiving activities may not always be associated with positive visions of the self or well-being but also take place in non-mutual relationships to one's detriment. Such non-mutuality may thus generate frustration and the relationship may be perceived as a burden (Kim et al., 2000), resulting in negative perceptions of one's interactional self-image. Future research needs to investigate possible ambiguous cognitive perceptions and affects regarding caregiving activities, in order to disinguish between the positive and negative consequences for self-concept and well-being.

\section{Limitations}

There are several limitations to consider in these two studies. First, while we used a one-year time lagged design, there is more need to explore the role of mattering regarding the general process of retirement with different longitudinal designs. For example, monthly measures of mattering during the two years before and after having entered retirement would be of particular interest, as our data enable only comparisons between groups of older workers and retirees but no evaluation of change across the retirement transition. For instance, Fazio (2010) found differences in mattering between young-old (i.e., 65-74 years), old (75-84) and old-old (85 and more) adults, with a gradual decrease in mattering with age. Notably, it would be interesting to explore the intraindividual change in mattering for older adults encountering physical decline, which may concretely diminish physical mobility and thus quantity of daily activities and social interactions. Further, different longitudinal designs may enable to investigate possible modifications in the role played by mattering on well-being over the retirement process, from an initial important role on cognitive aspects, to an important role for affective aspects of well-being once in retirement.

Second, self-administrated questionnaires were used, thus reporting subjective perceptions of retirement adjustment, retirement planning, social interactions, and mattering, rather than objective measurement. Future research may include others' (e.g., spouse, friends, and 
colleagues) ratings of retirees' and older employees' interpersonal mattering (i.e., mattering to specific individuals) and wellbeing, in order to obtain an external assessment of the role of mattering on retirement adjustment quality. Moreover, future studies need to compare the effects of social interactions with effects of individual (e.g., health), contextual (e.g., work centrality), and organizational (e.g., conditions of workforce exit) factors on the retirement process, as suggested by Wong and Earl's (2009) integrated model. Finally, future research may use more specific measures of caregiving activities and retirement planning. The person to whom care is given might be specified, which may enable to distinguish, for example, between help given to elderly parents or grandchildren, or between the help provided to family members versus friends or neighbors. Similarly, future studies may compare caregiving activities with more formal activities such as volunteering. Finally, scholars may examine the relationships between caregiving activities and mattering and well-being using shorter time lags (e.g., six months). Also, formal and informal types of retirement planning, and general and interpersonal mattering, may be distinguished.

Third, both our older worker and retiree samples represented rather privileged groups, given that a bit more than fifty percent had obtained a college or university degree in both samples and earned relatively high salaries. Indeed, previous literature reported that financial status contributes to higher retirement adjustment quality (Wang et al., 2011), because it may increase retirees' participation in different social spheres, thus enhancing their sense of social contribution. While we included income and education as potential control variables, it would be interesting to investigate the impact of social interactions on planning and adjustment through mattering with less privileged older worker and retiree groups.

Finally, we also need to take into account the cultural context in which our studies took place. Switzerland represents a particular context: Among OCDE countries, its employment rates of older workers aged 50 to 64 years are the second highest after Sweden (Styczynska, Riekhoff, Lis, \& Kaminska, 2013). In addition, average retirement age is around 64.1 years old for men and 62.6 years old for women, placing Switzerland at the third highest retirement ages in European countries after Norway and Sweden (Trageser, Hammer, \& Fliedner, 2012). We believe that it would be interesting to replicate our findings in more "early-exit" cultures of retirement, examining for instance whether perceptions of mattering may be more threatened during the retirement process in early-exit retirement cultures than in late-exit cultures (e.g., because people may be categorized as old when they still are and feel younger); or vice versa (e.g., because a lower importance may be placed on the work role in the country, diminution of this role may be less deleterious for one's interactional selfconcept).

\section{Practical Implications}

We suggest that career counselors investigate social interactions in depth with clients in the retirement process (e.g., identifying specific people in clients' social networks, exploring caregiving activities and the recognition derived from them). Overall, we urge practitioners to focus on mattering as the interactional dimension of self-concept, in order to improve older clients' subjective well- 
being. Career counselors may foster clients' understanding of how their life and retirement projects may matter to themselves and to others (Savickas, 2005). As suggested by Jung (2015), it could be useful for a client to learn about the mattering construct, because it may enlarge their perceptions of their work experiences within their relational and societal contexts. Thus, it is important that career counselors assess mattering, for instance through asking the five questions of the general mattering scale (Marcus, 1991) adapted in a semi-structured interview form. When perception of mattering appears to be low, Schlossberg (2009) proposed different strategies that may help retirees to replace their former source of mattering through work: beginning new activities that are close to work life, contributing to the community, initiating new relationships with family and friends, and finding inner meanings of mattering.

\section{Conclusion}

This work represents the first attempt to our knowledge to more closely investigate how and why mattering is related to both retirement planning and retirement adjustment. Our research demonstrated that mattering plays an important role for retirement adjustment but not for retirement planning. We found differences depending on group (older workers vs. retirees) and type of well-being regarding the role played by mattering in the relationship between social interactions and the retirement process; thus, revealing that positive social interactions (i.e., social support at work and general social support) are not enough for older workers to be satisfied with their life and for retirees to feel positive affect. In particular, our results suggest an initial important role of mattering on cognitive aspects of well-being before retirement, to an important role for affective aspects of wellbeing once in retirement.

\section{References}

Atchley, R. (1999). Continuity theory, self, and social structure. In C. Ryff \& V. Marshall (Eds.), The Self and Society in Aging Processes (pp. 145-158). Newbury Park, CA: Sage.

Blais, M. R., Vallerand, R. J., Pelletier, L. G., \& Brière, N. M. (1989). The satisfaction scale: Canadian-French validation of the Satisfaction with Life Scale. Canadian Journal of Behavioural Science/Revue Canadienne des Sciences du Comportement, 21, 210-223. doi: 10.1037/h0079854

Blustein, D. (2011). A relational theory of working. Journal of Vocational Behavior, 79, 1-17. doi: 10.1016/j.jvb.2010.10.004

Carstensen, L. L., Isaacowitz, D. M., \& Charles, S. T. (1999). Taking time seriously: A theory of socioemotional selectivity. American Psychologist, 54, 165-181. doi: 10.1037/0003-066X.54.3.165

Chen, Y., \& Feeley, T. H. (2014). Social support, social strain, loneliness, and well-being among older adults: An analysis of the Health and Retirement Study. Journal of Social and Personal Relationships, 31, 141161. doi: $10.1177 / 0265407513488728$

Chiesa, R., \& Sarchielli, G. (2008). Getting ready for retirement: The role of social support in anxiety management. Revista de Psicologia del Trabajo y de las Organizaciones, 24, 365-388. doi: 10.4321/S157659622008000300006

De Lange, A. H., Taris, T. W., Kompier, M. A., Houtman, I. L., \& Bongers, P. M. (2003). "The very best of the millennium": longitudinal research and the demandcontrol-(support) model. Journal of Occupational Health Psychology, 8, 282. doi: 10.1037/10768998.8.4.282

Diener, E. (1984). Subjective well-being. Psychological Bulletin, 95, 542-575. doi: 10.1037/00332909.95.3.542

Diener, E., Emmons, R. A., Larsen, R. J., \& Griffin, S. (1985). The Satisfaction With Life Scale. Journal of Personality Assessment, 49, 71-75. doi: 10.1207/s15327752jpa4901_13

Diener, E., Wirtz, D., Tov, W., Kim-Prieto, C., Choi, D.-W., Oishi, S., \& Biswas-Diener, R. (2010). New well-being measures: Short scales to assess flourishing and positive and negative feelings. Social Indicators Research, 97, 143-156. doi: 10.1007/s11205-0099493-y 
Dumitrache, C. G., Windle, G., \& Herrera, R. R. (2015). Do social resources explain the relationship between optimism and life satisfaction in community-dwelling older people? Testing a multiple mediation model. Journal of Happiness Studies, 16, 633-654. doi: 10.1007/s10902-014-9526-3

Ekerdt, D. J. (2010). Frontiers of research on work and retirement. The Journals of Gerontology Series B: Psychological Sciences and Social Sciences, 65, 6980. doi: $10.1093 /$ geronb/gbp109

Elliott, G., Kao, S., \& Grant, A.-M. (2004). Mattering: Empirical validation of a social-psychological concept. Self and Identity, 3, 339-354. doi: $10.1080 / 13576500444000119$

Fazio, E. M. (2007). Role occupancy, physical health and the diminishment of the sense of mattering in late life. (Doctoral Dissertation), University of Maryland. Retrieved from http://drum.lib.umd.edu/bitstream/handle/1903/7756/u mi-umd-5038.pdf?sequence $=1$

Fazio, E. M. (2010). Sense of mattering in late life. In W. R. Avison, C. S. Aneshensel, S. Schieman \& B. Wheaton (Eds.), Advances in the Conceptualization of the Stress Process (pp. 149-176). New York, NY: Springer.

Feeney, B. C., \& Collins, N. L. (2015). A new look at social support: A theoretical perspective on thriving through relationships. Personality and Social Psychology Review, 19, 113-147. doi: $10.1177 / 1088868314544222$

Flum, H. (2015). Relationships and career development: An integrative approach. In P. I. Hartung, M. L. Savickas \& W. B. Walsh (Eds.), APA Handbook of Career Intervention (Vol. 1, pp. 145-158). Washington, DC: American Psychological Association.

Grundy, E., \& Henretta, J. C. (2006). Between elderly parents and adult children: A new look at the intergenerational care provided by the 'sandwich generation'. Ageing \& Society, 26, 707-722. doi: $10.1017 /$ S0144686X06004934

Harel, Y., Shechtman, Z., \& Cutrona, C. (2011). Individual and group process variables that affect social support in counseling groups. Group Dynamics: Theory, Research, and Practice, 15, 297-310. doi: 10.1037/a0025058

Hobfoll, S. E. (2002). Social and psychological resources and adaptation. Review of General Psychology, 6, 307-324. doi: 10.1037//1089-2680.6.4.307

Howell, A. J., \& Buro, K. (2015). Measuring and predicting student well-being: Further evidence in support of the Flourishing Scale and the Scale of Positive and
Negative Experiences. Social Indicators Research, 121, 903-915. doi: 10.1007/s11205-014-0663-1

Humphrey, S. E., Nahrgang, J. D., \& Morgeson, F. P. (2007). Integrating motivational, social, and contextual work design features: A meta-analytic summary and theoretical extension of the work design literature. Journal of Applied Psychology, 92, 1332-1356. doi: 10.1037/0021-9010.92.5.1332

Jovanovic, V. (2015). Beyond the PANAS: Incremental validity of the Scale of Positive and Negative Experience (SPANE) in relation to well-being. Personality and Individual Differences, 86, 487-491. doi: 10.1016/j.paid.2015.07.015

Jung, A.-K. (2015). Interpersonal and societal mattering in work: A review and critique. The Career Development Quarterly, 63, 194-208. doi: 10.1002/cdq.12013

Kim, H.-K., Hisata, M., Kai, I., \& Lee, S.-K. (2000). Social support exchange and quality of life among the Korean elderly. Journal of Cross-Cultural Gerontology, 15, 331-347. doi: 10.1023/A:1006765300028

Lim, V. K. (2003). An empirical study of older workers' attitudes towards the retirement experience. Employee Relations, 25, 330-346. doi: $10.1108 / 01425450310483361$

Lipps, O., \& Pekari, N. (2013). Mode and incentive effects in an individual register frame based Swiss election study. FORS Working Paper Series, paper 2013-3. Lausanne: FORS.

Luhmann, M., Hofmann, W., Eid, M., \& Lucas, R. E. (2012). Subjective well-being and adaptation to life events: A meta-analysis. Journal of Personality and Social Psychology, 102, 592-615. doi: 10.1037/a0025948

Marcus, F. M. (1991). Mattering: Its measurement and theoretical significance for social psychology. Paper presented at the annual meeting of the Eastern Sociological Association, Cincinnati, $\mathrm{OH}$.

Marshall, S. K. (2001). Do I matter? Construct validation of adolescents' perceived mattering to parents and friends. Journal of Adolescence, 24, 473-490. doi: 10.1006/jado.2001.0384

Midlarsky, E., Kahana, E., \& Belser, A. (2015). Prosocial Behavior in Late Life. In D. A. Schroeder \& W. G. Graziano (Eds.), The Oxford Handbook of Prosocial Behavior (pp. 415-432). New York, NY: Oxford University Press.

Morgeson, F. P., \& Humphrey, S. E. (2006). The Work Design Questionnaire (WDQ): Developing and validating a comprehensive measure for assessing job design and the nature of work. Journal of Applied 
Psychology, 91, 1321-1339. doi: 10.1037/00219010.91.6.1321

Muthén, L. K., \& Muthén, B. O. (1998-2012). Mplus User's Guide. Seventh Edition. Los Angeles, CA: Muthén \& Muthén.

Office, S. F. S. (2015). Wage level by major region in 2012. Neuchâtel, Switzerland: Author.

Owens, T. J., Robinson, D. T., \& Smith-Lovin, L. (2010). Three faces of identity. Annual Review of Sociology, 36, 477-499. doi:

10.1146/annurev.soc.34.040507.134725

Parker, S. K., Andrei, D., \& Li, W. (2014). An overdue overhaul: Revamping work design theory from a time perspective. In A. J. Shipp \& Y. Fried (Eds.), Time and Work: How Time Impacts Individuals (Vol. 1). London, UK: Routledge/Taylor \& Francis

Pearlin, L. I., \& LeBlanc, A. J. (2001). Bereavement and the loss of mattering. In T. J. Owens, S. Stryker \& N. E. Goodman (Eds.), Extending self-esteem theory and research: Sociological and psychological currents (pp. 285-300). Cambridge, UK: Oxford University Press.

Piliavin, J. A., \& Siegl, E. (2007). Health benefits of volunteering in the Wisconsin longitudinal study. Journal of Health and Social Behavior, 48, 450-464. doi: $10.1177 / 002214650704800408$

Pinquart, M., \& Schindler, I. (2007). Changes of life satisfaction in the transition to retirement: A latentclass approach. Psychology and Aging, 22, 442-455. doi: 10.1037/0882-7974.22.3.442

Potocnik, K., \& Sonnentag, S. (2013). A longitudinal study of well-being in older workers and retirees: The role of engaging in different types of activities. Journal of Occupational and Organizational Psychology, 86, 497521. doi: 10.1111/joop.12003

Preacher, K. J., \& Hayes, A. F. (2008). Asymptotic and resampling strategies for assessing and comparing indirect effects in multiple mediator models. Behavior Research Methods, 40, 879-891. doi: 10.3758/BRM.40.3.879

Rayle, A. D. (2005). Adolescent gender differences in mattering and wellness. Journal of Adolescence, 28, 753-763. doi: 10.1016/j.adolescence.2004.10.009

Rayle, A. D., \& Chung, K.-Y. (2007). Revisiting first-year college students' mattering: Social support, academic stress, and the mattering experience. Journal of College Student Retention: Research, Theory and Practice, 9, 21-37. doi: 10.2190/X126-5606-4G368132

Reitzle, M., Korner, A., \& Vondracek, F. W. (2009). Psychological and demographic correlates of career patterns. Journal of Vocational Behavior, 74, 308-320. doi: 10.1016/j.jvb.2009.02.005

Rohall, D. E. (2003). Macro- and micro-social conditions affecting individual sense of mattering during a period of downsizing. Current Research in Social Psychology, 9, 1-17.

Rosenberg, M., \& McCullough, B. (1981). Mattering: Inferred significance and mental health among adolescents. Research in Community \& Mental Health, 2, 163-182.

Ryan, R. M., \& Deci, E. L. (2000). Self-determination theory and the facilitation of intrinsic motivation, social development, and well-being. American Psychologist, 55, 68-78. doi: 10.1037/0003-066X.55.1.68

Sargent, L. D., Bataille, C. D., Vough, H. C., \& Lee, M. D. (2011). Metaphors for retirement: Unshackled from schedules. Journal of Vocational Behavior, 79, 315324. doi: 10.1016/j.jvb.2011.03.002

Savickas, M. L. (2005). The theory and practice of career construction. In M. L. Savickas, S. D. Brown \& R. W. Lent (Eds.), Career Development and Counseling: Putting Theory and Research to Work (pp. 42-70). Hoboken, NJ: John Wiley \& Sons Inc; US.

Schlossberg, N. K. (1989). Marginality and mattering: Key issues in building community. New Directions for Student Services, 48, 5-15. doi: $10.1002 / \mathrm{ss} .37119894803$

Schlossberg, N. K. (2009). Revitalizing retirement: Reshaping your identity, relationships, and purpose. Washington, DC: American Psychologist Association.

Scholz, U., Kliegel, M., Luszczynska, A., \& Knoll, N. (2012). Associations between received social support and positive and negative affect: Evidence for age differences from a daily-diary study. European Journal of Ageing, 9, 361-371. doi: 10.1007/s10433-012-02366

Schultheiss, D. E. (2007). The emergence of a relational cultural paradigm for vocational psychology. International Journal for Educational and Vocational Guidance, 7, 191-201. doi: 10.1007/s10775-007-91237

Schulz, U., \& Schwarzer, R. (2003). Social support in coping with illness: The Berlin Social Support Scales (BSSS). Diagnostica, 49, 73-82. doi: 10.1026//00121924.49.2.73

Schwarz, B., Albert, I., Trommsdorff, G., Zheng, G., Shi, S., \& Nelwan, P. R. (2010). Intergenerational support and life satisfaction: A comparison of Chinese, Indonesian, and German elderly mothers. Journal of Cross-Cultural Psychology, 41, 706-722. doi: $10.1177 / 0022022110372197$ 
Schwarzer, R., Schulz, U., \& Katsap, B. (2000). Echelles Berlinoises de Soutien Social. Retrieved 02/04, 2015, from http://userpage.fu-berlin.de/ health/soc_f.htm

Shankland, R., \& Martin-Krumm, C. (2012). Assessing optimal functioning: Positive psychology scales validated in French. Pratiques Psychologiques, 18, 171-187. doi: 10.1016/j.prps.2012.02.004

Shultz, K. S., \& Adams, G. A. (2007). Aging and work in the 21st century. Mahwah, $\mathrm{NJ}$ : Lawrence Erlbaum Associates.

Shultz, K. S., \& Wang, M. (2011). Psychological perspectives on the changing nature of retirement. American Psychologist, 66, 170-179. doi: 10.1037/a0022411

Silva, A. J., \& Caetano, A. (2013). Validation of the Flourishing Scale and Scale of Positive and Negative Experience in Portugal. Social Indicators Research, 110, 469-478. doi: 10.1007/s11205-011-9938-y

Silverstein, M., Conroy, S. J., \& Gans, D. (2012). Beyond solidarity, reciprocity and altruism: Moral capital as a unifying concept in intergenerational support for older people. Ageing \& Society, 32, 1246-1262. doi: 10.1017/S0144686X1200058X

Stegmann, S., van Dick, R., Ullrich, J., Charalambous, J., Menzel, B., Egold, N., \& Wu, T. T.-C. (2010). The Work Design Questionnaire: Introduction and validation of a German version. Zeitschrift fur Arbeitsund Organisationspsychologie, 54, 1-28. doi: 10.1026/0932-4089/a000002

Styczynska, I., Riekhoff, A.-J., Lis, M., \& Kaminska, A. (2013). The impact of institutional and socio-ecological drivers on activity at older ages, Neujobs working papers (Vol. D17.3). Warsaw, Poland: CASE Network Reports.

Sumi, K. (2014). Reliability and validity of Japanese versions of the Flourishing Scale and the Scale of Positive and Negative Experience. Social Indicators Research, 118, 601-615. doi: 10.1007/s11205-0130432-6

Taylor, J., \& Turner, R. (2001). A longitudinal study of the role and significance of mattering to others for depressive symptoms. Journal of Health and Social Behavior, 42, 310-325. doi: 10.2307/3090217

Taylor, M. A., \& Schaffer, M. (2012). Planning and adaptation to retirement: The post-retirement environment, change management resources, and need-oriented factors as moderators. In M. Wang (Ed.), The Oxford Handbook of Retirement (pp. 249266). New York, NY: Oxford University Press.

Telef, B. B. (2013). The Scale of Positive and Negative Experience: A validity and reliability study for adolescents. Anadolu Psikiyatri Dergisi, 14, 62-68. doi: 10.5455/apd.36692

Thoits, P. A. (2011). Mechanisms linking social ties and support to physical and mental health. Journal of Health and Social Behavior, 52, 145-161. doi: 10.1177/0022146510395592

Tovel, H., \& Carmel, S. (2014). Maintaining successful aging: The role of coping patterns and resources. Journal of Happiness Studies, 15, 255-270. doi: 10.1007/s10902-013-9420-4

Trageser, J., Hammer, S., \& Fliedner, J. (2012). Altersrücktritt im Kontext der demografischen Entwicklung [Retirement in the context of demographic trends]. Zürich, Switzerland: Federal Social Insurance Office, Switzerland.

van den Bogaard, L., Henkens, K., \& Kalmijn, M. (2014). So now what? Effects of retirement on civic engagement. Ageing and Society, 34, 1170-1192. doi: 10.1017/S0144686X13000019

van Solinge, H. (2013). Adjustment to retirement. In M. Wang (Ed.), The Oxford Handbook of Retirement (pp. 311-324). New York, NY: Oxford University Press.

Wang, M., Henkens, K., \& van Solinge, H. (2011). Retirement adjustment: A review of theoretical and empirical advancements. American Psychologist, 66, 204-213. doi: 10.1037/a0022414

Wang, M., \& Shi, J. (2014). Psychological research on retirement. Annual Review of Psychology, 65, 209233. doi: 10.1146/annurev-psych-010213-115131

Wang, M., \& Shultz, K. S. (2010). Employee retirement: A review and recommendations for future investigation. Journal of Management, 36, 172-206. doi: 10.1177/0149206309347957

Wöhrmann, A. M., Deller, J., \& Wang, M. (2013). Outcome expectations and work design characteristics in postretirement work planning. Journal of Vocational Behavior, 83, 219-228. doi: 10.1016/j.jvb.2013.05.003

Wong, J. Y., \& Earl, J. K. (2009). Towards an integrated model of individual, psychosocial, and organizational predictors of retirement adjustment. Journal of Vocational Behavior, 75, 1-13. doi: 10.1016/j.jvb.2008.12.010 